\title{
LAS JUNTAS DE ACCIONISTAS, OBJETO DE INNOVACIÓN
}

\author{
SHAREHOLDER MEETINGS, A MATTER OF INNOVATION
}

\author{
ANDRÉS JARA BAADER ${ }^{1}$
}

\section{INTRODUCCIÓN}

Las juntas de accionistas se encuentran vinculadas de forma estrecha con la gobernabilidad de las sociedades anónimas, toda vez que constituyen la expresión máxima de fiscalización y control por parte de aquellas personas denominadas accionistas.

La instancia de reunión de los accionistas, entendiendo por tales a aquellos titulares de una o varias acciones de una sociedad cuyo capital se representa en títulos accionarios, es el instante preciso donde el real sentido de la sociedad logra dilucidarse. En efecto, es en este momento donde cada uno de los accionistas, socios, puede participar e influir activamente en el desarrollo del objeto social y determinar el rumbo de timón que los administradores han de materializar en su ejercicio diario.

Esta representación puede parecer algo drástica, sin embargo, debido a la existencia del incentivo natural hacia la pereza y el oportunismo al administrar lo ajeno, los accionistas han presenciado cómo administradores inescrupulosos postergan el interés social en pos del interés particular. Claro está que tal escenario fatalista también tolera excepciones, pues no son pocos aquellos administradores que logran superar con creces el crecimiento esperado de una industria particular, o que con cierta obstinación, logran superar crisis financieras internas o externas que, sin su astucia, no hubiesen concluido en un próspero futuro.

\footnotetext{
${ }^{1}$ Profesor de Derecho Comercial, Pontificia Universidad Católica de Chile. Agradezco la ayuda prestada por don Guillermo Pizarro, ayudante en mi cátedra de Derecho Comercial y activo colaborar en la investigación que permitió dar origen al presente texto.
}

Con todo, la participación activa de los accionistas en la sociedad, sean estos accionistas minoritarios, mayoritarios o controladores, debe necesariamente ser un efecto buscado. Más aún, debiese ser el lineamiento preponderante en toda obra legislativa que pretenda realzar el gobierno corporativo. En efecto, creemos que tal premisa puede lograr una expresión adecuada en las juntas de accionistas, cuyo rol es, sin lugar a duda, fundamental.

En efecto, sin un apoyo legislativo adecuado, factores tan comunes como los costos de transacción asociados a la participación en juntas o prácticas habituales de free riding desincentivan el actuar activo de los accionistas minoritarios.

Son innumerables los autores que han abocado su estudio a la efectividad y relevancia de las juntas de accionistas, pero son pocos aquellos autores que han logrado identificar la necesidad de ir incorporando a tales juntas elementos de innovación disponibles en nuestro entorno. El presente trabajo pretende precisamente concentrar su análisis en la posibilidad de implementar en Chile juntas de accionistas que cuenten con un apoyo tecnológico contundente por medio del cual se permita asegurar una mayor participación a los accionistas $y$, consecuencialmente, tutelar de forma algo más extensa los derechos e intereses de los accionistas minoritarios ${ }^{2}$.

${ }^{2}$ Maug, Ernst G. and Rydgyist, Kristian, Do Shareholders Vote Strategically? Voting Behavior, Proposal Screening, and Majority Rules (September 17, 2008). Mannheim Finance Working Paper No 2006-15; ECGI - Finance Working Paper No 31/ 2003; EFA 2004 Maastricht Meetings Paper No 2516. ZETSCHE, Dirk A., Shareholder Passivity, Cross-Border Voting and the Shareholder Rights Directive (Julio 21, 2008). Journal of Corporate Law 
En concreto, abordaremos los avances que han sido incorporados por medio de la Ley No 20382 en el régimen de las sociedades anónimas, prestando especial atención a aquellos elementos de innovación que creemos pueden constituir un cambio efectivo. También observaremos las experiencias en el derecho comparado, para luego, concluir nuestro análisis con ciertas propuestas y conclusiones particulares relativas a la innovación tecnológica en el campo de las juntas de accionistas.

\section{EVOLUCIÓN}

Las juntas de accionistas son estudiadas habitualmente como el ente fiscalizador de la administración en las sociedades anónimas, la que por su parte recae en el directorio. En efecto, es la junta de accionistas aquella asamblea que se estima constituye la máxima expresión de voluntad y gobernabilidad dentro de la sociedad anónima. A ella le deben orden el directorio y los demás estamentos administrativos dentro de la sociedad y es a ella que compete el conocer y aprobar la gestión de los negocios sociales por medio de la aprobación del balance y memoria anual.

De tal forma, debe reconocérsele a la junta de accionistas el papel de órgano superior dentro de la sociedad anónima y, consecuentemente, el de fuente de inspiración y manifestación directa del interés social.

Lata es la discusión doctrinaria respecto de qué es o qué debe ser entendido por interés social. Al respecto creemos adecuada la interpretación que hace el profesor Alcalde, quien concluye que: "[...] el fin o interés de la sociedad no es otro que la obtención de utilidades en la explotación de su giro y la participación de los socios en ellas a través de la proporción que les competa según sus estatutos"3. Conti-

Studies, Vol. 8, No 2, 2008; CBC-RPS No 0031. BEBCHUK, Lucian A., The Case for Increasing Shareholder Power. Harvard Law Review, Vol. 118, No 3, pp. 833-914, Enero 2005; Harvard Law and Economics Discussion Paper No 500.

3 AlCAlde, Enrique. La Sociedad Anónima; Autonomía privada, interés social y conflictos de interés. Editorial Jurídica de Chile, Santiago (2008) p. 46. nuando, Alcalde, haciendo alusión al artículo 2091 del Código Civil, señala: "De este modo, el precepto transcrito nos sugiere, sin duda de clase alguna, que es el 'interés común' de los socios $-\mathrm{y}$ por tanto ningún interés extrasocietario- aquel que debe ser calificado como 'interés social'[...]" ${ }^{4}$. Así, estimamos que ha de permanecer siempre claro que el interés social es el interés común de los socios, por lo que toda confusión con el interés particular de un grupo de socios, un socio, el directorio o los administradores personificados en la figura del gerente general, constituye una interpretación inadecuada. Lo anterior implica necesariamente que el interés social debe encontrarse en directa comunión con la gestión administrativa $y$, en su defecto, con la labor de fiscalizadora.

Por su parte, teniendo a la vista lo dicho con anterioridad, debe entenderse que la radicación de la administración en el directorio es tan solo un indicio de aquella la necesidad imperiosa de contar con una administración ágil y efectiva en el entorno empresarial, lo que habitualmente se entiende contrapuesto con la intervención permanente de la junta de accionistas $^{5}$. Sin embargo, hay que considerar que en grandes empresas cuyo capital esta repartido entre un elevado número de accionistas donde cada uno de ellos posee una fracción poco significativa del capital, de forma que no les permite controlar las actuaciones de los directivos de la empresa, los intereses de los directivos corporativos y de los accionistas pueden divergir ampliamente. Así, mientras que los directivos quedan conceptuados como personas que van en busca de poder, prestigio y dinero, y por ello tratan de imponer a la empresa unos objetivos más acordes con los suyos propios y consistentes con sus propias motivaciones, los accionistas están interesados solo en los beneficios ${ }^{6}$. Las preferencias por el ta-

\footnotetext{
${ }^{4}$ Idem. Supra nota 2.

5 Puelma, Álvaro. Sociedades, Tomo II, Sociedad Anónima. Tercera edición, Editorial Jurídica de Chile, Santiago (2003) p. 655.

${ }^{6}$ Berle, A. y MEANS, G. The modern corporation and private property. Macmillan, New York (1932). COASE, R.H. The Nature of The Firm. Economica, 4 (1937) pp. 386-405.
} 
maño -como fuente de poder o como medio para conseguir mayores salarios-, junto con la suficiente discrecionalidad para influir en él, constituyen los fundamentos de la teoría managerial de la empresa, que se revela como una de las primeras explicaciones sobre el origen de la ineficiencia a que da lugar a la separación entre propiedad y control $^{7}$.

Lo anterior no constituye sino un reconocimiento evidente del principal problema implícito en la administración de bienes de terceros, el equilibrio entre fiscalización y administración eficiente y oportuna. Ello a su vez se vincula de forma estrecha con el denominado problema del agente-principal, cual presupone la concurrencia de tres conocidas características, a saber: (a) la asimetría de la información; (b) el desconocimiento de las intenciones verdaderas del agente; y (c) la dificultad de identificar al agente con el riesgo inherente a la propiedad del capital.

Uno de los primeros autores en detectar el referido problema fue Smith, quien analizó el caso específico de quienes reducen su participación económica al comprar acciones. Al respecto señalaba: "[...] la mayor parte de estos accionistas [...] no se interesan en sus asuntos y están satisfechos con recibir el dividendo semestral o anual que los directivos consideran conveniente pagarles. Esta ausencia total de inconvenientes y riesgos, más allá de una suma muy limitada, anima a muchas personas a volverse empresarios en una sociedad por acciones, personas que en ningún caso arriesgarían su fortuna en una sociedad particular [...] Ahora bien, no es razonable esperar que los directivos de estas compañías, al manejar mucho más dinero de otras personas que de ellos mismos, lo vigilen con el mismo ansioso cuidado con el que frecuentemente vigilan el suyo los socios de una empresa particu-

\footnotetext{
7 BAUMOL, W. Business behavior, value and grow. Mcmillan. New York (1959). Williamson, O. The economics of discretionary behavior: managerial objectives in a theory of the firm", PrenticeHall (1964). Pratt, J.W. y Zeckhauser, R.J. Principals and agents: the structure of business. Harvard Business School Press (1991).
}

lar [...] En consecuencia, el manejo de los negocios de esas compañías siempre está caracterizado en alguna medida por la negligencia y la prodigalidad" 8 .

Creemos que el problema del agenteprincipal debe servir de base para construir la estructura de administración de la sociedad, toda vez que en ellas concurren de forma ineludible todos los elementos que caracterizan tal relación. Por de pronto, el capital de la sociedad y sus bienes pertenecen de forma indirecta a los accionistas, quienes encargan la administración de los mismos a terceros designados como directores. A su vez, tales terceros delegan parte importante de sus funciones en gerentes y ejecutivos principales, los que usualmente descargan la materialización diaria de sus funciones en otros empleados. Esta cadena piramidal de responsabilidades y atribuciones debe ser regulada, pues de lo contrario puede derivarse en derroche o generación de riesgos innecesarios, los cuales los socios no deberían estar dispuestos a asumir.

Así, la función del legislador adquiere importancia, toda vez que una adecuada y concienzuda técnica legislativa puede impedir, o al menos reducir, las imperfecciones que dan origen al problema del agente-principal.

De esta forma, surge la necesidad de mejorar la estructura jerárquica actual, donde las decisiones de administración y disposición puedan contar con el beneplácito de quienes pueden verse directamente afectados por las mismas, esto es, todos y cada uno de los accionistas.

Más aún, se requiere también perfeccionar los niveles de fiscalización, control y sanción que sopesen los incentivos perversos que se generan como consecuencia de aquellas tres características propias del problema del agente-principal ya mencionado.

Muchas veces el análisis legislativo y la labor de generación normativa ha llevado implícito el reconocimiento del problema tantas veces mencionado, sin embargo, muy pocas

8 Smith Adam. La Riqueza de las Naciones. ed. Carlos Rodríguez Braun, Alianza Editorial, Madrid (1994). 
veces ha sido tratado desde una perspectiva económica adecuada.

Dado lo anterior, creemos que las juntas de accionistas deben y pueden jugar un rol más activo en la administración de la sociedad $y$, por su parte, los accionistas, no importando la prorrata de su participación, pueden tomar un rol determinante en las decisiones sociales. Para ello es necesario que dicha participación sea prácticamente sustentable, proveyéndosele a los accionistas medios idóneos, de fácil acceso y eficiente resultado para la emisión de opiniones informadas y fundadas, con la entrega de información relevante y continua a través de los mismos medios que permitirían tal participación.

La evolución legislativa debe buscar la disminución en la asimetría de información y el aumento en la fiscalización por parte de los accionistas de las sociedades anónimas. Tal evolución ha experimentado en el último tiempo un incremento notable, generalmente atribuible a la ocurrencia de eventos poco gratos, donde accionistas minoritarios se han visto afectados, o incluso, donde los mismos accionistas, o sus representantes en el directorio, no han tenido oportuno conocimiento de lo que ocurre en el giro diario de la sociedad. Por lo anterior, creemos posible señalar que a la fecha el resultado legislativo ha obedecido a una conducta básicamente reactiva, más que preventiva.

En este sentido, en Chile, las principales innovaciones en materia de información a nivel de las juntas de accionistas fueron incorporadas por la Ley No 19.705, del año 2001. Luego, nuevos avances han sido incorporados por la Ley No 20.382, del año 2009. En efecto, dicho cuerpo legal ha introducido y corregido elementos relevantes de la Ley $\mathrm{N}^{\circ}$ 18.046, marcando con ello una tendencia interesante hacia la innovación en materia de juntas de accionistas. Con todo, es indudable que las modificaciones introducidas por la Ley No 20.382 no son suficientes para lograr la implementación adecuada de actividades "en red" o por "medios virtuales" que faciliten a las sociedades y a los accionistas la participación eficiente y oportuna que hemos venido esbozando. Sin embargo, los avances ya deno- tan un cambio remarcable en cuanto a la forma en que los accionistas pueden participar o emitir su voto en las juntas de accionistas y, consecuentemente, un cambio en la visión del legislador.

Estimamos que la Ley No 20.382, introdujo 2 novedades relevantes: (1) la posibilidad de que las juntas de accionistas puedan autoconvocarse, celebrándose válidamente aquellas juntas donde la totalidad de los accionistas hayan comprometido su asistencia, ocasión en la cual deja de ser necesario el cumplimiento de formalidades de convocatoria $^{9}$; y (2) la autorización que se ha dado a las sociedades anónimas abiertas para que sus accionistas emitan votos a distancia, para lo cual ha sido necesario que la Superintendencia de Valores y Seguros apruebe los sistemas mediante los cuales se materialice tal facul$\operatorname{tad}^{10} 11$.

Desde nuestra perspectiva, las novedades indicadas fijan el curso correcto en materia de introducción de mecanismos de innovación en los gobiernos corporativos de las sociedades anónimas. Sin embargo, también estimamos que los pasos a seguir pueden involucrar un grado considerablemente superior de avance. A título meramente ejemplar, destacamos la experiencia del estado de Delaware en los Estados Unidos de América, donde la factibilidad de desarrollar asambleas de accionistas se ha extendido incluso a la web, con reproducción online en tiempo real de los discursos y cuentas de la administración, más la posibilidad de emitir votos e interactuar con preguntas directas a distancia ${ }^{12}$.

\footnotetext{
${ }^{9}$ Ley 20.382, Art. $2 \mathrm{~N}^{\circ}$ 40, 2009.

${ }^{10}$ Ley 20.382, Art. $2 \mathrm{~N}^{\circ} 42,2009$.

${ }^{11}$ Norma de Carácter General No 273 , de fecha 13 de enero de 2010, regula sistemas de votación en juntas de accionistas, Superintendencia de Valores y Seguros.

12 Delaware Corporation Law, Title 8, Chapter 1, Subchapter VII, Section 211(a)(1) and (a)(2). Disponible en http://delcode.delaware.gov (última visita 29 de diciembre de 2010).
} 


\section{MOVIMIENTOS ACTUALES Y LAS JUNTAS DE ACCIONISTAS}

Son principalmente dos los factores que han hecho renacer el interés actual en las juntas de accionistas: (1) la globalización; y (2) la digitalización. En efecto, con el tiempo y en lo que a globalización se refiere, la realidad de composición de propiedad de las sociedades anónimas se ha hecho más dispersa y trasciende fronteras. Así, no es extraño encontrar sociedades anónimas constituidas en países donde sus accionistas no son residentes ni domiciliados y donde los accionistas de las mismas se encuentran dispersos por el mundo. Es en tales circunstancias donde la posibilidad de participar y actuar a distancia cobra notoria relevancia. Por su parte la digitalización, entendiendo por tal al proceso de incorporación de tecnologías de información y comunicación que no requieren la reunión en tiempos y lugares físicos determinados, sino que permite la generación de espacios virtuales, lo que ha motivado la oferta de soluciones logísticas y de reducción de costos antes inimaginables, contribuyendo con la entrega de mecanismos adecuados para la participación accionaria acti$\mathrm{va}^{13}$.

Tradicionalmente, a las juntas de accionistas se les reconocen tres funciones: información, comunicación y decisión o voto ${ }^{14}$. Cada una de tales funciones adquiere relevancia en la solución del mencionado problema del agente-principal, más aún, un adecuado desarrollo de las funciones de información, comunicación y decisión permite alinear de forma debida los intereses particulares de quienes se involucran en la administración de la sociedad anónima, con aquel interés común o interés social previamente definido.

La relevancia de las funciones de las juntas de accionistas es tal, que legislaciones

13 ZETSCHE Dirk. Corporate Governance in Cyberspace - A Blueprint for Virtual Shareholder Meetings, Center of Business and Corporate Law Research Paper Series, Heinrich-Heine-Universität-Düsseldorf. CBC-RPS No 0011 (2005). Disponible en SSRN: http://ssrn.com/abstract=747347 (última visita 11 febrero 2010) p. 9 algo más avanzadas en la discusión de estos temas han emprendido un camino directamente orientado a potenciar el rol de los accionistas. Caso ejemplar es el de la Unión Europea, donde la comisión europea ha intentado armonizar los derechos de los accionistas dentro de Europa. Así, considerando que las juntas de accionistas pertenecen al día a día de las sociedades y que más y más compañías han ofrecido medios electrónicos para participar en la adopción de decisiones corporativas, se ha determinado como particularmente importante tener un claro entendimiento respecto de las diferentes aproximaciones a los medios electrónicos de participación de accionistas a través de diversas jurisdicciones ${ }^{15}$. No obstante ello, autores como Zetsche reconocen que el principal problema de introducir medios tecnológicos para la participación de los accionistas en la administración de la sociedad pasa por entender que los propios accionistas dudan en depender y confiar exclusivamente en medios-web para el ejercicio de sus derechos. Al mismo tiempo, la administración, esto es, el directorio y la gerencia de las sociedades anónimas tienen pocos incentivos para ofrecer medios idóneos y eficientes para la implementación de medios-web para el ejercicio de los derechos de los accionistas ${ }^{16}$. En efecto, lograr un régimen eficiente de juntas de accionistas virtuales y una adecuada participación de los accionistas requiere ajustes a los procedimientos tradicionales. En principio, deben identificarse al menos las siguientes características: (a) que la junta sea liberada de las restricciones de tiempo y lugar normalmente reguladas por las legislaciones; (b) logra integrar

14 FERRAN, Ellis. The role of the Shareholder in Internal Corporate Governance: Enabilng Shareholders to make better informed decisions, EBOR (2003), p. 491; y NOACK, Ulrich. Information, Kommunikation, Entscheidung - Zur Corporate Governance der Hauptversammlung europäischer Aktiengesellschaften, Center of European Business Law (ed.), Bonn (2003). Disponible en http://ssrn.com/abstract $=646723$ (última visita 11 febrero 2010), pp. 74-75.

${ }^{15}$ Supra nota 13, p. 7.

${ }^{16}$ Supra nota 13 , p. 8. 
las funciones de análisis e inversionistas institucionales free-riding; y (c) lograr replicar la contabilidad cara a cara de los administradores, lo que se asocia con las juntas de accionistas tradicionales ${ }^{17}$.

Adicionalmente, debe considerarse que la propiedad accionaria ampliamente dispersa genera accionistas racionalmente apáticos, por cuanto el resultado de la junta de accionistas estará generalmente determinado por votos fijados con anterioridad por inversionistas institucionales. Asimismo, es común encontrar accionistas minoritarios que desean participar en cierta medida en el proceso de adopción de decisiones, pero que probablemente se vean imposibilitados de asistir a la junta personalmente. Las razones, no viven en la ciudad donde se lleva a cabo la junta, la junta es celebrada en días hábiles en que ausentarse de las labores profesionales es difícil, el costo de trasladarse y estar presente en la junta es muy alto, entre otras. Por lo anterior, el resultado no es solo que los accionistas que están habilitados y con posibilidades de asistir y que no representan a la totalidad de los accionistas asistan a las juntas, sino que además hay un importante potencial para que las juntas sean capturadas por grupos con intereses especiales ${ }^{18}$.

Por último, creemos que debe también considerarse que en la actualidad existe reduci$\mathrm{da}$ jurisprudencia, incluso a nivel mundial, respecto del proceso mismo de las juntas de accionistas y de la tutela de los derechos de accionistas minoritarios en circunstancias donde hayan sido utilizados medios tecnológicos de comunicación. Con todo, a título meramente ejemplar, es posible encontrar precedentes jurisprudenciales aislados como el fallo de la Corte de Apelaciones Inglesa (Byng v London Life Ass. Ltd. [1990] Ch 170) donde en 1990 se aceptó como válida una junta

\footnotetext{
17 Supra nota 13 , p. 8.

18 BOROS, Elizabeth. Virtual Shareholder Meetings: Who decides how companies make decisions? Disponible en http://www.austlii.edu.au/au/journals/ MULR/2004/9.html (última visita 2 de julio de 2010).
}

anual general de accionistas celebrada en varias salas interconectadas por vía audiovisual que facultaba a aquellos en cada pieza para escuchar y ver qué sucedía en las otras salas. Estas dificultades se complementan con la concurrente ausencia de disposiciones legales abiertas y flexibles que toleren la incorporación de avances e innovación tecnológica. Un ejemplo claro de ello es lo que sucede en Australia, donde no hay disposición expresa que permita a las juntas de accionistas ser celebradas en "ningún lugar", como podría ser un medio virtual, pero sí se autoriza a que ellas sean celebradas en varios lugares ${ }^{19}$. Por lo anterior, dependiendo de cómo se interpreten los requisitos legales, muchas veces es o no posible argumentar que las disposiciones legales vigentes podrían extenderse a una junta de accionistas completamente virtual ${ }^{20}$.

\section{FLUJOS DE INFORMACIÓN ENTRE LA SOCIEDAD Y LOS ACCIONISTAS}

Autores como Zetsche han identificado en análisis de legislaciones comparadas la posibilidad de clasificar el flujo de información a los accionistas en dos principales categorías, a saber, pull y $p u s h^{21}$. El primero implica una participación activa de los accionistas, esto es, la necesidad de que los accionistas soliciten la información de la sociedad. El segundo, en cambio, implica una actitud negativa por parte de los accionistas, siendo la sociedad, normalmente presionada por la ley, la que debe proveer a los accionistas con la información. Es este último método el que prima en Chile. En efecto, es posible observar en dispersas disposiciones legales atingentes a la sociedad anónima la obligación de mantener a disposición de los accionistas toda su información. Ahora bien, lo anterior no obsta a que los accionistas puedan solicitar la información que estimen pertinente en la medida que ella no sea res-

\footnotetext{
19 Australian Corporation Act, Section 249S. Disponible en http://www.austlii.edu.au/au/legis/cth/ consol_act/ca2001172/s249s.html (última visita 12 de julio de 2010)

${ }^{20}$ Idem. Supra nota 14.

21 Idem. Supra nota 13.
} 
tringida por ley.

A mayor abundamiento, ejemplos claros respecto de disposiciones legales que demuestran la aplicación del criterio push son las siguientes: (i) el artículo $27 \mathrm{~A}$ de la Ley No 18.046, que dispone: "Las juntas de accionistas citadas para considerar la adquisición de acciones de su propia emisión, deberán pronunciarse sobre el monto o porcentaje máximo a adquirir, el objetivo y la duración del programa, el que no podrá ser superior a cinco años, así como del precio mínimo y máximo a pagar por las acciones respectivas, materias sobre las cuales el directorio de la sociedad deberá dar información amplia y detallada [...]"; (ii) el artículo 42 de la Ley No 18.046, señala: "Los directores no podrán: [...] 3) Inducir a los gerentes, administradores, ejecutivos principales y dependientes, o a los inspectores de cuentas o auditores externos y a las clasificadoras de riesgo, a rendir cuentas irregulares, presentar informaciones falsas y ocultar información; 4) Presentar a los accionistas cuentas irregulares, informaciones falsas y ocultarles informaciones".; (iii) el artículo 46, inciso primero, de la Ley No 18.046, dispone: "El directorio deberá proporcionar a los accionistas y al público, las informaciones suficientes, fidedignas y oportunas que la ley y, en su caso, la Superintendecia determinen respecto de la situación legal, económica y financiera de la sociedad". Debe recordarse además que esta disposición se hace igualmente aplicable a los gerentes de la sociedad anónima y a todas aquellas personas que hagan sus veces ${ }^{22}$. (iv) el artículo 54 de la citada Ley, señala en su inciso primero: "La memoria, balance, inventario, libros y los informes de los auditores externos y, en su caso, de los inspectores de cuentas, quedarán a disposición de los accionistas para su examen en la oficina de la administración de la sociedad [...]". Por su parte, el inciso final complementa señalando: "En el caso de las sociedades anónimas abiertas, la memoria, el informe de los auditores externos y los estados financieros auditados de la sociedad, deberán ponerse a disposición de los accionistas en el

${ }^{22}$ Artículo 50, Ley No 18.046. sitio de Internet de las sociedad que dispongan de tales medios". Todas las disposiciones anteriores constituyen un testimonio fiel respecto de primar el criterio push en la legislación sobre sociedades anónimas.

El determinar cuál es el criterio de flujo de información que rige en nuestra legislación no deja de ser relevante y tener relación con el tema que nos convoca. En efecto, el hecho de imperar el criterio ya mencionado demuestra que el interés del legislador es mantener a los accionistas, esto es, a aquellas personas cuyo interés común representa el interés social, actual y completamente informados sobre el quehacer de la sociedad. Mas es destacable que nuestro legislador aboque tal precisión en los deberes de información que recaen sobre administradores y directores. Ello, sumado a lo señalado en párrafos anteriores, permite concluir que la orientación del legislador valora la participación de los accionistas de la sociedad anónima y que realza la posibilidad de que accionistas adopten sus decisiones con acceso a información fidedigna y oportuna. Es precisamente aquella orientación la que motiva la introducción de mecanismos que faciliten de forma eficiente la participación de los accionistas en la sociedad y, particularmente, la discusión para la implementación de medios tecnológicos que habiliten a accionistas para interactuar de forma directa y entusiasta con los administradores que les representan. Sobre esta base, no sería factible plantear la ausencia de interés y voluntad legislativa como un obstáculo para analizar y promover innovaciones como las que en este texto se analizan.

\section{VOTACIÓN A DISTANCIA Y AVANCES EN CHILE}

Como veremos, desde nuestra perspectiva, la principal innovación en materia de gobiernos corporativo en Chile, se encuentra constituida por la introducción ampliada de medios tecnológicos en las funciones y relaciones de comunicación entre accionistas y administradores. Manifestación de dicha creatividad jurídica constituye la posibilidad de publicar información en las páginas de Internet que las sociedades posean o incluso la al- 
ternativa de emitir votos a distancia.

En lo que a votación se refiere, a nivel global, se identifican fundamentalmente dos modalidades de votación y participación. La primera está constituida por el denominado "voto electrónico directo" y, la segunda, corresponde a una versión más extrema de realidad virtual, esto es, la "junta de accionista virtual”. En principio, la implementación del voto electrónico exige las mismas medidas de seguridad que la industria bancaria ha tomado en sus operaciones en línea, requiriéndose que los accionistas obtengan identidades y conexiones seguras ${ }^{23}$. Dado lo anterior, toda intención de cuestionar la efectividad de los sistemas para votación electrónica carece de fundamentos reales, cuando ella se sustenta sobre la base de que los sistemas o la tecnología no es lo suficientemente avanzada para garantizar los derechos de los accionistas. Por su parte, se observa en las legislaciones comparadas que el uso de cualquiera de los dos modelos mencionados se encuentra siempre sujeto al consentimiento de los socios o accionistas ${ }^{24}$. Lo anterior, no parece ser una excepción en el derecho chileno, toda vez que los derechos de los accionistas deben siempre sobreponerse por sobre decisiones de administración que afecten la regularidad del proceso de votación.

La experiencia que demuestran diversas jurisdicciones revela que el voto directo electrónico no ha logrado aceptación general. Son primordialmente dos las razones que habitualmente se aluden para justificar el rechazo a estos sistemas de voto directo electrónico: (1) los errores en la convocatoria o procedimiento de la junta, pues cuando no se adaptan a la legislación vigente pueden ser causales que invalidan la misma, o incluso derivar en acciones de perjuicios contra la sociedad o sus administradores; y (2) el voto directo requiere una expansión del significado de la expresión "junta"

23 KANE, Margaret, "Virtual Shareholder Meetings Flop," CNETNews (Septiembre 2001) (Disponible en http://news.cnet.com/virtual-shareholdermeetings- flop/2100-1023_3-272745.html) (última visita 16 de abril de 2010).

${ }^{24}$ Supra nota 13, p. 21. desde un entendimiento físico tradicional a un entendimiento que comprenda los asistentes virtuales a través de Internet ${ }^{25}$.

En Chile, el análisis de las causales habituales expresadas en el párrafo anterior merece cierta detención. Primeramente, corresponde señalar que en virtud de la Ley No 18.046 y su respectivo reglamento, las juntas de accionistas se encuentran sujetas a formalidades estrictas respecto de su convocatoria y citación $^{26}$. No obstante ello, la evolución legislativa ha llevado a flexibilizar las normas de antaño, permitiéndose actualmente incluso la omisión de aquellas formalidades de citación requeridas y autorizándose la autoconvocatoria cuando la totalidad de los accionistas concu$\operatorname{rran}^{27}$. Por lo demás, en aquellos casos donde las normas de convocatoria y citación deben ser observadas, la omisión de ciertas formalidades en el caso de sociedades anónimas abiertas, no invalida la citación. Con todo, si creemos que la expansión del término tradicional de "junta" desde su entendimiento físico a una concepción virtual, requiere mayores avances en el derecho chileno, siendo actualmente inadecuado concluir que nuestro ordenamiento jurídico toleraría la figura de una junta virtual. Avances en este sentido han sido emprendidos por legislaciones como la francesa que contempla la posibilidad de que accionistas participen en una junta por medio de videoconferencia o otros medios de telecomunicaciones que les permita ser identificados, debiéndose en tales casos considerársele como presente en la referida junta para el fin del cálculo de

\footnotetext{
25 Supra nota 13, p. 23.

${ }^{26}$ Artículo 59, Ley No 18.046.

27 Artículo 60, Ley No 18.046.

28 Artículo L225-107 (Ley No 2.001-420 del 15 de mayo de 2001, Artículo $1151^{\circ}$ Diario Oficial de 16 de mayo de 2001) I. Todo accionista podrá votar por correspondencia, por medio de un formulario cuyo contenido será definido por decreto adoptado en Conseil d'État. Las disposiciones contrarias de los estatutos se tendrán por no puestas. Para el cálculo del quórum, solo se tendrán en cuenta los formularios que hayan sido recibidos por la sociedad con antelación a la celebración de la junta, en las condiciones de plazo definidas por decreto
} 
quórums y mayorías ${ }^{28}$.

Las interpretaciones anteriores se hacen aún más evidentes cuando se analizan disposiciones atingentes del derecho chileno. Así, la Ley No 18.046, en el inciso final del artículo 64 señala que: "La Superintendencia, mediante norma de carácter general, podrá autorizar a las sociedades anónimas abiertas, para establecer sistemas que permitan el voto a distancia, siempre que dichos sistemas resguarden debidamente los derechos de los accionistas y la regularidad del proceso de votación”. Luego, se desprende del artículo 62, inciso final, que: "Toda votación que se efectúe en junta debe operar por medio de un sistema que asegure la simultaneidad en la emisión de votos o bien en forma secreta, debiendo siempre el escrutinio llevarse a cabo en un solo acto público [...]". Por su parte, la Norma de Carácter General No 273, emitida por la Superintendencia de Valores y Seguros con fecha 13 de enero de 2010 , instruye para el caso de votación a distancia que: "[...] las sociedades anónimas abiertas podrán, como parte de los sistemas autorizados de votación, contemplar mecanismos electrónicos de votación a distancia, siempre que estos cumplan los principios de autenticación, control de acceso, confidencialidad, integridad y no repudio a que se refiere la Norma de Carácter General No 114”. Finalmente, la Norma de Carácter General No 114, de fecha 29 de marzo de 2001, instruye que se entenderá por sistemas de autenticación, control de acceso, confidencialidad, integridad y no repudio, los siguientes: “a) autenticación, aquel en que el fiscalizado deberá verificar y

adoptado en Conseil d'État. Los formularios que no indiquen un sentido determinado para el voto o que expresen una abstención serán considerados como votos negativos. II. Si los estatutos lo previeran, serán considerados presentes para el cálculo del quórum y de la mayoría los accionistas que participen en la junta por medio de videoconferencia o por medios de telecomunicación que permitan su identificación y cuya naturaleza y condiciones de aplicación sean determinados por decreto adoptado en Conseil d'État. Disponible en http:// www.legifrance.com/initRechCodeArticle.do (última visita 15.02.2010). asegurarse respecto de la identidad de sus clientes. b) control de acceso: el que tenga por objeto garantizar que solo podrán tener acceso al sistema aquellas personas que cuenten con la autorización necesaria y solo respecto a las áreas que les compete en las que se encuentren autorizados. c) confidencialidad, el que garantice que la información contenida en las transacciones solo podrá ser vista por el destinatario del mensaje. d) integridad, el que garantice que la información no es y no será alterada durante la transmisión. Asimismo, se deberá contar con servicios de respaldo de información. e) no repudio, aquel que garantice que el emisor de la información no podrá negar su autoría y contenido". Para cumplir con los sistemas dispuestos en las letras precedentes, la sociedad anónima debe contar con un certificado de sitio Web seguro, otorgado por una entidad certificadora calificada o de reconocido prestigio, donde la información sea transmitida en forma encriptada con algoritmos de encriptación avanzados, tales que no permitan descifrar dicha información, a través de medios tecnológicos, en un período inferior a un año. Adicionalmente, la Superintendencia ha determinado que para dar cumplimiento a lo dispuesto con anterioridad, la sociedades anónimas deben incorporar softwares y hardwares de cortafuegos o firewall, en conjunto con políticas internas de seguridad, que permitan controlar los accesos al sistema y base de datos por parte de usuarios internos y externos. Así, para los efectos de implementar el voto a distancia, la entidad interesada debiese presentar una solicitud a la Superintendencia por la cual se requiriese la autorización de utilizar un sistema determinado para la materialización del voto a distancia. Solo una vez presentada tal solicitud esta sería derivada al departamento de informática de la misma Superintendencia, quienes analizarán si se cumplen con los requisitos de la Norma de Carácter General No 114. Es también recomendable presentar junto con la solicitud un certificado de web seguro. Sin embargo, no hay claridad ni un listado de

${ }^{29}$ Un ejemplo puede estar constituido por compañías como Verisign. 
qué entidades pueden ser clasificadas como "certificadoras calificada o de reconocido prestigio" 29 .

En virtud de lo expuesto, es posible concluir que la implementación del voto electrónico a distancia es perfectamente posible de ser implementado en Chile para las sociedades anónimas abiertas en la medida que ellas cumplan cabalmente con todos los requisitos ya señalados. En cuanto a las sociedades anónimas cerradas, creemos que es posible determinar que en ellas primará la voluntad de los accionistas en todo aquello que no se contrapusiere a las disposiciones legales ya mencionadas.

\section{UNA ALTERNATIVA EXTREMA}

Con anterioridad abordamos el voto electrónico, cual constituye un primer paso en la búsqueda de innovación a nivel de la participación de accionistas en sus sociedades anónimas. Sin embargo, hoy ya existen ciertos avances futurísticos antes inimaginables. Un ejemplo claro es la posibilidad de sostener e implementar juntas de accionistas íntegramente virtuales, donde la existencia de un lugar físico pasa a ser irrelevante y en la cual la participación de los accionistas puede permitir altos quórums sin presencia física requerida. Una junta de accionistas virtual no tiene lugar en un espacio físico determinado, sino que se materializa en la "web", sea lo que este concepto signifique. En efecto, el término "web" es una reducción del concepto "world wide web" o "www". Una página web es principalmente un documento o fuente de información, generalmente en formato HTML y que puede contener hiperenlaces a otras páginas web. Dicha página web, es accesible desde un dispositivo físico, una intranet, o Internet, generalmente mediante el protocolo HTTP. A su vez un sitio web es un conjunto de páginas web, típicamente comunes a un dominio o subdominio en la World Wide Web. Una página web es un documento HTML/XHTML accesible generalmente mediante el protocolo HTTP de Internet. Todos los sitios web públicamente accesibles constituyen una gigantesca "World Wide Web" de información. Final- mente, a las páginas de un sitio web se accede desde un URL raíz común llamado portada, que normalmente reside en el mismo servidor físico. Los URL organizan las páginas en una jerarquía, aunque los hiperenlaces entre ellas controlan cómo el lector percibe la estructura general y cómo el tráfico web fluye entre las diferentes partes de los sitios.

Bajo el modelo más extremo de junta de accionista virtual, la materialidad de la junta se desvanece, pues es íntegramente reemplazada por un procedimiento basado en esta web. Así, accionistas y directores deliberan y se comunican específicamente y exclusivamente por la web ${ }^{30}$. Actualmente, juntas de accionistas virtuales, bajo el modelo indicado solo se encuentran disponibles en USA y Canadá ${ }^{31}$.

Sin perjuicio de lo atractivo que puede resultar implementar juntas de accionistas cien por ciento virtuales. El punto a dilucidar es si es que es posible pensar que el interés y relevancia en las juntas de accionistas anuales (ordinarias) pueden aumentar con el aumento del uso de juntas de accionistas virtuales ${ }^{32}$.

Puntos como los planteados con anterioridad suelen ser comunes en estudios vinculados a la participación de los accionistas y su interés de actuar o intervenir con la conducción de las sociedades. En efecto, tanto el voto electrónico como las juntas de accionistas virtuales, entendidos como mecanismos tendientes a facilitar la interacción y participación de los accionistas, solo tienen sustento y sus costos justificación, en la medida que exista por parte de los accionistas un verdadero interés

\footnotetext{
30 Supra nota 13, p. 27.

31 S.211 (A) (1) SENT. 2. TITLE 8 DelGCL (Delaware, USA); S.132 (5) CBCA (Canadá); y BIRNHAK, Daniel Adam. Online Shareholder meetings: corporate law anomalies or the future of governance? Rutgers Computer \& Technology Law Journal. ISSN 0735-8938 (2003).

32 HANSEN, Rick E., Revisiting Virtual Stockholder Meeting, Insights. The Corporate \& Securities Law Advisor, Vol. 23, No 9, pp. 2-8 (Septiembre 2009), Disponible http://proquest.umi.com.ezproxy. puc. $\mathrm{cl} / \mathrm{pqdlink}$ ? did $=1884417891 \& \mathrm{sid}=2 \& \mathrm{Fmt}=$ $3 \&$ clientId $=52738 \& \mathrm{RQT}=309 \& \mathrm{VName}=\mathrm{PQD}$ (última visita 3 de enero de 2010), p. 5.
} 
de participar e influir en la gestión de las sociedades. De ahí la relación directa con el comportamiento de los accionistas en función de la concentración de propiedad en las sociedades y sus efectos en estas materias. Adicionalmente, estamos convencidos de que en la medida que los medios para participar en las juntas de accionistas son de fácil acceso, mayor debiese ser la participación en ellas de todos aquellos accionistas minoritarios que habitualmente dejan de tomar parte por circunstancias como las que ya hemos expuesto.

Por su parte, es importante destacar que Chile actualmente es uno de los países con mayores tasas de penetración de Internet en Latinoamérica, lo que permite concluir que las barreras de acceso a los medios tecnológicos imprescindibles para participar en juntas de accionistas virtuales o para utilizar el voto electrónico no son reales ${ }^{33}$.

\section{CONCENTRACIÓN EN MERCADO Y SUS EFECTOS EN LA PARTICIPACIÓN}

Como señaláramos con anterioridad, ya en el año 1776, Adam Smith describía el conflicto de intereses entre los propietarios (principales) y los administradores (agentes), al mencionar la falta de diligencia de estos cuando no eran simultáneamente propietarios. Tanto en Europa, como en América Latina, la regla general parece ser la presencia de un accionista controlador y el principal conflicto de agencia, la expropiación de los accionistas minoritarios ${ }^{34}$. Más aún, es perfectamente posible señalar que la concentración de propiedad accionaria en Chile corresponde a un promedio aproximado del $41 \%$ de las acciones en

33 Ver el World Internet Project Report publicado con fecha 2 de marzo de 2010 en http:// www.worldinternetproject.net/_files/_News/37/ wip2010_long_press_release_v2.pdf

34 BenaVides, Julián, Concentración de la propiedad $y$ desempleo contable. El caso latinoamericano. Borradores de Economía y Finanzas. ISSN 1900-1568, Primera edición. Cali, Colombia (2005) p. 3

35 Estudio de Concentración de Propiedad Accionaria CGC UC año 2010. que se encuentra representado el capital de las sociedades anónimas que componen el IGPA pero que no en pocas sociedades el índice de concentración llega a cifras cercanas al 70\% ${ }^{35}$. Por su parte, autores como Shleifer y Vishny (1986), señalaban que niveles sustanciales de propiedad eliminan el problema del free riding que aqueja a los pequeños accionistas, dándole a los accionistas mayoritarios suficientes incentivos para monitorear las acciones de los gerentes, toda vez que solo en los accionistas controladores o mayoritarios los beneficios de monitoreo exceden los costos asociados a este $^{36}$. Más aún, si consideramos que los administradores de grandes compañías suelen no actuar por los intereses de sus empleadores, los accionistas, y que los costos de agencia que surgen de este conflicto de intereses siguen siendo sustanciales. Especialmente, cuando ningún accionista tiene más de un porcentaje mínimo de propiedad de la sociedad, ninguno de ellos tiene suficiente iniciativa de controlar a la administración, pues el beneficio que reporta ello es muy pequeño ${ }^{37}$.

Todo lo anterior obedece a una causal analizada con destreza por Demstez y Lehn (1985) quienes hipotetizan que la concentración de la propiedad es producto del riesgo del negocio, del tamaño del mismo, y de la industria a la que pertenece. El efecto del riesgo debería ser no-monotónico, es decir, inicialmente, a mayor riesgo, mayor potencial de costos de agencia, puesto que la posibilidad de decisiones discrecionales del gerente es mayor, por lo que los propietarios incrementan óptimamente su porcentaje de propiedad. Sin embargo, niveles demasiado altos de riesgo, im-

36 Shleifer, Andreyi y ViShny, Robert, Large Shareholders and Corporate Control, Journal of Political Economy (1986) pp. 461-488.

37 Latham, Mark, The Internet Will Drive Corporate Monitoring (Mayo 1999). Disponible en SSRN: http://ssrn.com/abstract $=166248$ or doi:10.2139/ssrn.166248 (última visita 3 de enero de 2010) p. 1.

38 Demstez, Harold y LeHn, Kenneth. The Structure of Corporate Owernship: Causes and Consequences. The Journal of Political Economy, 93 (1985), pp. 1155-1177. 
plican, en caso de alta concentración, una diversificación de riesgo subóptima, por lo que los propietarios reducen su participación ${ }^{38}$. Las razones teóricas del efecto de la concentración de la propiedad sobre el desempeño, están relacionadas con la teoría de agencia. En principio, a mayor concentración en manos del gerente, menores conflictos de agencia y por ende mejor desempeño ${ }^{39}$. Desde el punto de vista de los accionistas controladores el efecto es también positivo puesto que una mayor concentración se asocia a una mayor capacidad de monitoreo sobre el gerente; sin embargo, el efecto sobre los accionistas minoritarios, al incrementar la capacidad de expropiación, puede dar lugar a un efecto negativo que los desmotiva a participar en la sociedad. También excesiva concentración puede llevar a atrincheramientos por los controladores que pueden no estar ya sujetos a las fuerzas de mercado, una reducción de iniciativa del gerente por exceso de monitoreo, o una excesiva aversión al riesgo ${ }^{40}$. Todo lo cual explica con mayor énfasis la necesidad de dotar a los accionistas, especialmente minoritarios, de herramientas que faciliten en forma extrema su participación en la sociedad.

Es así necesario determinar cuál es la razón de la falta de incentivo de los accionistas a participar. En estricto rigor, tal razón obedece a que el costo para obtener más información con respecto a una propuesta es muy alto para el accionista promedio. Este accionista no tiene recursos para investigar a fondo un hecho particular, y el costo de proponer que esa información le sea enviada es alto ${ }^{41}$. Por de

39 Jensen, M.C. y Meckling, W.H. Theory of the firm: managerial behavior, agency cost and ownership structure. Journal of Financial Economic, 3 (2), (1976) pp. 305-360.

${ }^{40}$ Supra nota 13, p. 13.

41 PoEndS, George. Shareholder Voting over the Internet. A Proposal for Increasing Shareholder Participation in Corporate Governance. Alabama Law Review, Volume 49:2 (2007), pp. 673-700. Disponible en Alabama Law Review http:// www.law.ua.edu/lawreview/articles/Volume\%2049/ Number\%202/kobler.pdf (última visita 4 de enero de 2010) p. 686. pronto, ¿es realmente necesario aumentar la participación de los accionistas? Desde una perspectiva societaria, creemos que aumentar el acceso a más información, debiese generar un impacto positivo en el valor de la sociedad, pues como consecuencia directa de mayor volumen y mejor calidad de información, sería posible ejercer una concienzuda y directa fiscalización de la administración, lo que probablemente que traiga como resultado una mejoría en la toma de decisiones corporativas. Incluso es posible concluir que cuando un amplio rango de ideas es llevada adelante para tomar una decisión particular mejora el proceso de decisión aumentando la información con la que quienes toman las decisiones puedan hacerlo. Adicionalmente, el aumento en la cantidad de información disponible y el bajo costo para transmitir y obtener esa información tiene el potencial para mitigar muchos de los problemas que hoy afectan la participación de los accionistas ${ }^{42}$. Finalmente, la disponibilidad de información es un gran nivelador, trayendo a los accionistas minoritarios al mismo nivel de acceso que los accionistas mayoritarios.

\section{CONCLUSIONES RESPECTO DEL ATRACTIVO EN EL VOTO ELECTRÓNICO Y LAS JUNTAS DE ACCIONISTAS VIRTUALES}

A partir de los antecedentes revisados y consideraciones efectuadas anteriormente, parece adecuado concluir que la opción de celebrar juntas de accionistas virtuales, en contraposición a la celebración de juntas de accionistas físicas, y el incentivar el uso de voto electrónico, provee a la sociedad de herramientas prácticas para diseñar juntas de accionistas masivas y útiles, como también para entregar elementos que permitan conocer de forma más profunda las necesidades de la compañía ${ }^{43}$.

Claro está que los costos de elaborar la base de información que se necesita para soste-

\footnotetext{
42 Supra nota 34, p. 692.

43 Supra nota 23, p. 6-7.
} 
ner los sistemas informáticos necesarios y esenciales para la implementación de juntas de accionistas virtuales o voto electrónico no son menores, pero son bajos en relación al mejoramiento que reflejarían las políticas corporativas, la reducción de costos en papelería y correo, como en relación con los beneficios directos que emanan de un adecuado sistema de monitoreo sobre el actuar de la compañía, lo que ciertamente influirá en equilibrios entre ganancias y metas de la compañía ${ }^{44}$.

En efecto, quizás la más importante característica de utilizar Internet como herramienta de comunicación e información es su bajo costo final y accesibilidad. Por su parte, desde una perspectiva tecnológica, si la compañía toma seriamente la implementación de juntas de accionistas virtuales o voto electrónico, la tecnología deberá facilitar el acceso a los accionistas y permitirá replicar a través de ellas la experiencia de una junta de accionistas en persona, permitiendo a los accionistas asistir, tomar la palabra, hacer preguntas, proponer nuevas inversiones, y decidir a través de su voto. Mejorada la tecnología para desarrollar juntas de accionistas virtuales, se permitirá un mayor acceso e interacción entre la administración de la compañía y sus inversionistas, es decir, entre el agente y el principal. Con ello las compañías permitirán a sus accionistas participar en las juntas de accionistas en tiempo real, haciendo preguntas, comentando las decisiones de administración e incluso votando durante su celebración ${ }^{45}$.

\section{BIBLIOGRAFÍA CITADA}

AlCAlde, Enrique. La Sociedad Anónima; Autonomía privada, interés social y conflictos de interés. Editorial Jurídica de Chile, Santiago (2008) p. 46.

BAUMOL, W. Business behavior, value and grow. MacMillan. New York (1959).

BEBCHUK, Lucian A., The Case for Increasing Shareholder Power. Harvard Law Review,

44 Supra nota 32 , p. 3.

45 Supra nota 26, pp. 4-5.
Vol. 118, No 3, pp. 833-914, Enero 2005; Harvard Law and Economics Discussion Paper No 500.

BENAVIDEs, Julián, Concentración de la propiedad y desempleo contable. El caso latinoamericano. Borradores de Economía y Finanzas. ISSN 1900-1568, primera edición. Cali, Colombia (2005) p. 3.

BIRNHAK, Daniel Adam. Online Shareholder meetings: corporate law anomalies or the future of governance?. Rutgers Computer \& Technology Law Journal. ISSN 0735-8938 (2003).

Berle, A. y Means, G. The modern corporation and private property. MacMillan, New York (1932).

BOROS, Elizabeth. Virtual Shareholder Meetings: Who decides how companies make decisions?. Disponible en http:// www.austlii.edu.au/au/journals/MULR/ 2004/9.html (última visita 2 de julio de 2010).

COASE, R.H. The Nature Of The Firm. Economica, 4 (1937) pp. 386-405.

DemsteZ, Harold y LeHn, Kenneth. The Structure of Corporate Owernship: Causes and Consequences. The Journal of Political Economy, 93 (1985), pp. 1155-1177.

FERRAN, Ellis. The role of the Shareholder in Internal Corporate Governance: Enabilng Shareholders to make better informed decisions, EBOR (2003), p. 491.

HANSEN, Rick E., Revisiting Virtual Stockholder Meeting, Insights. The Corporate \& Securities Law Advisor, Vol. 23, No 9, pp. 2-8 (Septiembre 2009), Disponible http:// proquest.umi.com.ezproxy.puc.cl/pqdink? did $=1884417891 \&$ sid $=2 \& F m t=3 \&$ clientId $=52738 \& R Q T=309 \& V N a m e=P Q D$ (última visita 3 de enero de 2010), p. 5.

Jensen, M.C. y Meckling, W.H. Theory of the firm: managerial behavior, agency cost and ownership structure. Journal of Financial Economic, 3 (2), (1976) pp. 305-360.

KanE, Margaret, "Virtual Shareholder Meetings Flop," CNETNews (Septiembre 2001) (Disponible en http://news.cnet.com/virtual-shareholdermeetings- flop/21001023_3-272745.html) (última visita $16 \mathrm{de}$ 
abril de 2010).

LATHAM, Mark, The Internet Will Drive Corporate Monitoring (Mayo 1999). Disponible en SSRN: http://ssrn.com/abstract $=166248$ or doi: $10.2139 /$ ssrn. 166248 (última visita 3 de enero de 2010) p. 1.

MAUG, Ernst G. and Rydgyist, Kristian, Do Shareholders Vote Strategically? Voting Behavior, Proposal Screening, and Majority Rules (September 17, 2008). Mannheim Finance Working Paper No 2006-15; ECGI - Finance Working Paper No 31/ 2003; EFA 2004 Maastricht Meetings Paper No 2516.

NOACK, Ulrich. Information, Kommunikation, Entscheidung - Zur Corporate Governance der Hauptversammlung europäischer Aktiengesellschaften, Center of European Business Law (ed.), Bonn (2003). Disponible en http://ssrn.com/abstract=646723 (última visita 11 febrero 2010), p. 74-75.

POENDS, George. Shareholder Voting over the Internet. A Proposal for Increasing Shareholder Participation in Corporate Governance.
Alabama Law Review, Volume 49:2 (2007), pp. 673-700. Disponible en Alabama Law Review http://www.law.ua.edu/ lawreview/articles/Volume\%2049/Number\%202/kobler.pdf (última visita 4 de enero de 2010). p. 686.

Pratt, J.W. y Zeckhauser, R.J. Principals and agents: the structure of business. Harvard Business School Press (1991).

Puelma, Álvaro. Sociedades, Tomo II, Sociedad Anónima. Tercera edición, Editorial Jurídica de Chile, Santiago (2003) p. 655.

SHLEIFER, Andreyi y VisHnY, Robert, Large Shareholders and Corporate Control, Journal of Political Economy (1986) pp. 461-488.

SMITH, Adam. La Riqueza de las Naciones. ed. Carlos Rodríguez Braun, Alianza Editorial, Madrid (1994).

Williamson, O. The economics of discretionary behavior: managerial objectives in a theory of the firm", Prentice-Hall (1964).

Zetsche, Dirk. Corporate Governance in Cyberspace - A Blueprint for Virtual Shareholder Meetings, Center of Business and Corporate Law Research Paper Series, Heinrich-Heine-Universität-Düsseldorf. CBC-RPS No 0011 (2005). Disponible en SSRN: http://ssrn.com/abstract $=747347$ (última visita 11 febrero 2010) p. 9.

Zetsche, Dirk A., Shareholder Passivity, Cross-Border Voting and the Shareholder Rights Directive (Julio 21, 2008). Journal of Corporate Law Studies, Vol. 8, No 2, 2008; CBC-RPS No 0031. 